\title{
A Study of the Cross-Integration of Film and Architecture
}

\author{
WANG Lu \\ School of Architecture, Nanyang Institute of Technology \\ Received: May 16, 2021 \\ Accepted: June 8, 2021 \\ Published: November 30, 2021
}

To cite this article: WANG Lu. (2021). A Study of the Cross-Integration of Film and Architecture. Asia-Pacific Journal of Humanities and Social Sciences, 01: 3, 066-071, DOI: 10.53789/j.1653-0465.2021.0103.007

To link to this article: https://doi.org/10.53789/ j.1653-0465.2021.0103.007

Abstract: Film and architecture are complementary to each other. They create a landscape in a specific space dimension, the static "scene" and the dynamic "scene". Both can create visual effects and space touch. Through comparative analysis and with the help of different concepts in the two fields, this study adopts a new model to achieve breakthroughs in film and architecture to deepen the understanding of their cultural connotation. In this way, it will make film and architecture stay in harmony and contribute to their development, offering more cultural support for social harmony.

Keywords: movie; architecture; artistry; cross-integration

Notes on the contributor: WANG Lu, a full-time doctoral student majoring in art at Qingzhou University, South Korea, is currently a lecturer in the School of Architecture, Nanyang Institute of Technology. Her academic interest lies in interior architecture, film architecture, and creative design.

\section{破“景”重圓 電影和建築的交叉融合研究}

\section{王 璐}

南陽理工學院建築學院

摘 要: 電影和建築是彼此交叉和融合發展的藝術門類,電影藝術和建築藝術就像是存在於某個空間維度的風景, 一個是静態的 “景”, 另一個則是動態的。二者分別是以營造可視化效果和空間觸感而建立的。因而, 本研究通過 比較分析法, 借助於兩個領域裹的不同的概念, 打破他們傅統的固有模式, 使電影和建築兩門㙯術門類彼此有新的 突破。研究目的是對雨者的文化内涵進行更深層次的挖掘, 找到二者交融共生的特性, 讓電影和建築在未來領域 有更多發展的可能, 使得它們為社會和諧共生提供更多元化的人文積澱。

關鍵词: 電影; 建築; 藝術性; 交叉融合

\section{引言}


對一定的人群, 滿足人們觀感和觸感的需求, 並且反映一定的内容。因此二者就不可避免地成為文化研究 的對象之一, 早前已經有電影建築學領域的出現, 但本文主要探究二者的共融性特徵, 同時二者既互相影響 又各自獨立, 又有著在各自領域所特有的特徵, 對於建築和電影的研究, 有助於未來對新興交叉學科的學 習, 以及對新媒體技術對空間的改造和創新提供一定的理論依據, 更有助於建築和電影的創新和發展。

\section{一、電影與建築的關係}

電影作為一種視覺媒介, 理解和表達角色內在世界的主要方式是視覺線索, 同時裏面會大面積採用建 築空間作為背景鋪熱, 電影在運用建築空間的時候, 事實上它是通過建築來承載對於電影中的人物形象、以 及他心理、生理、性格和社會諸多因素的隱喻和詮釋。在電影中不同的人物角色表達上,需要有不同的空間 來視托出身處空間中的不同人物。因此, 在電影表達上, 不僅僅有視聽和視覺語言, 電影往往比建築所使用 的形式語言更為複雜, 並具有無法比擬的優越性。並且也只有在電影中才可以捕捉到動態的鏡像效果, 對 於熱衷於電影的發燒友來說, 有一個真相是, 在幾乎不同類型的電影中, 建築永遠是不變的主題, “流水的電 影, 鐵打的建築, 似乎涵蓋了電影的全部題材。建築作為電影故事情節展開的場所和框架, 它對於電影的重 要性遠遠超過了對於電影的其他敘事手法。比如很多年前的科幻電影裏的場景和建築,多年後在現實生活 中這些建築就真的存在於我們的現實生活中, 那些科幻電影裏的一些建築跟普利茲克建築獎獲得者建築師 紮哈.哈迪德的建築風格如出一轍, 例如她的作品辛辛那提當代藝術中心 (如圖 1、2)。因此, 電影裏的幻想 主義和未來派建築就有很大的類似之處。

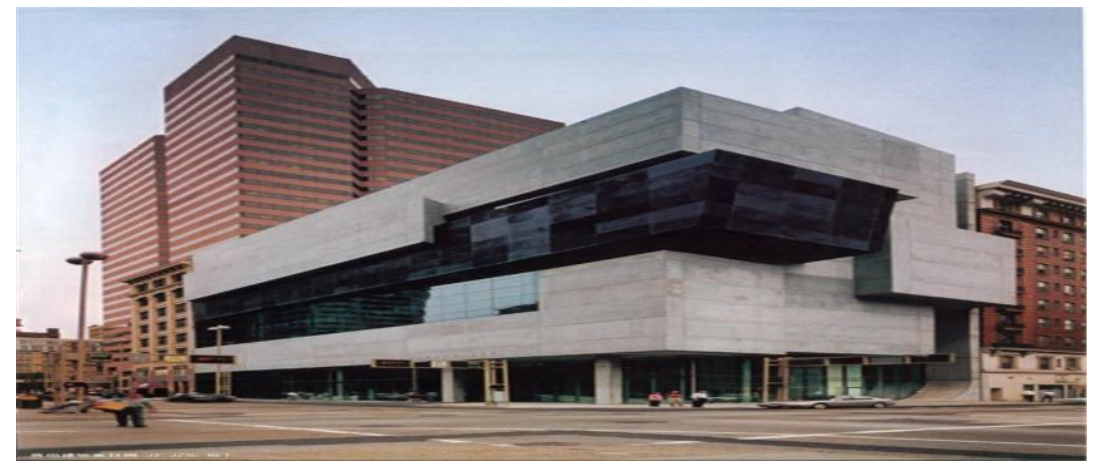

圖 1 紮哈・哈迪德的辛辛那提當代藝術中心建築外部

（來源: https://baike.baidu.com/item/紮哈・哈迪德? fromId=1179804)

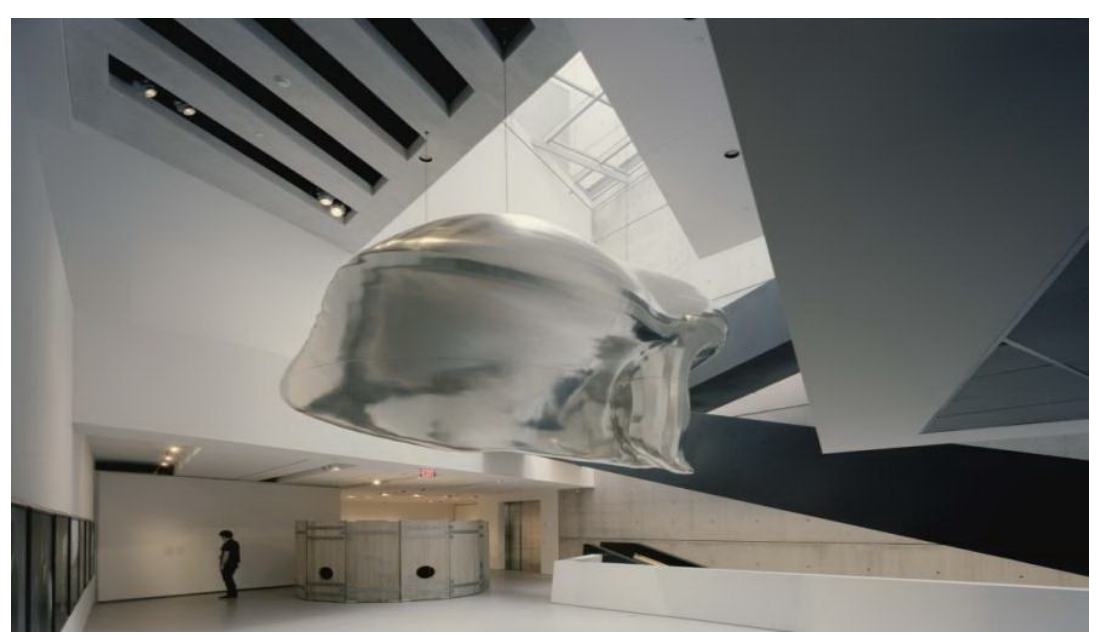

圖 2 紮哈 - 哈迪德的辛辛那提當代藝術中心建築内部

( 來源: https://baike.baidu.com/item/禁哈・哈迪德? fromId=1179804) 
我們在研究電影和建築時, 不能只瞭解他們單獨存在時的概念, 而是要知道兩者有一個共同的母體就 是美學。二者的藝術形式是有獨立性的,但同時他們二者也不可分割。除了它們的藝術共通性,電影和建 築文化也同樣不可分割, 電影是研究城市文化的很好依據, 不同國家拍攝的電影都會展示各自國家的特有 建築, 美國拍攝的電影就會以自由女神像以及摩天大樓作為電影主題背景, 而在中國香港, 可能會以維多利 亞灣的香港匯豐大廈作為拍攝取景, “電影其實是一組圖片在一定的頻率下連續放映產生的視覺效果。真 正產生電影的空間、時間、情節等等的是人的大腦,通過大腦對於視覺和聲音信息的認知建立起來的” ${ }^{1}$ 可見 建築是電影空間的一個基調; 那麼從人的主體角度來看,建築的空間、時間、内涵,不僅僅是簡單地通過神經 系統被認知的視覺和聽覺, 還有觸摸感、氣味等, 而這個是在電影裏無法涉及的感知感。“只有當人和建築 互動的時候, 才會產生。對於一個建築空間來說, 如果僅僅是簡單地從人的視覺考慮的話, 也只是由一系列 的圖像在視網膜上的成像來被眾人所識別的, 只不過存在的真實感是接近無窮大的。” 由此可見, 建築和電 影的區別在於互動性的真實性存在, 這是區別於虛擬現實環境中的互動性和畫面的真實性。

對電影來說, 畫面和場景都是連續的, 時間也隨著畫面場景變化而進行時間穿越, 這裏的故事就是畫面 本身。而建築不存在於場景的變化, 它的空間隨著建築本身一直持續著, 可以說這個建築在進行著時間的 凝固,很明顯兩者的區別就在於一個是“靜”, 一個是“動”, 這種靜態和動態的變化會發生轉化。

\section{二、空間中的建築表現}

無論是地球上的生物, 和廣哀的無垠的太空宇宙, 一切都存在於空間中, 自古以來, 人類透過各種媒介 去感知周圍的空間, 存在於這個空間內部, 並且思考著自己在空間內部發生的各種行為活動, 甚至隨著思考 的加深, 在逐漸改變這個世界, 以此滿足更多人們日益進化所需要的不同需求。受空間限制, 但又同時由反 作用空間具備改造空間的能力。建築大師阿爾托說: “老的東西不會再生,也不會消失, 曾經有過的總會以 新的形式再次出現。” (2)這種新的形式的再次出現其實就是指的創造, 空間也就使人類的建造行為產生了意 義。更具體地說, 人類所創造的空間都是為了滿足生理和心理需求而創造的, 建築就是把人可以集中在這 個空間內部進行生產和生活的中樞空間, 而建築本身充滿著實用性和藝術性。儘管我們可能往往會忽略掉 跟我們密切相關的居住空間, 但不可否認建築空間影響著我們, 並且一定程度上決定著人類的精神活動。 人們從建築空間中滿足了生理、心理上的需求,並且更高層次的建築空間甚至滿足了人們精神上的審美。 雖然這種審美情趣很難有言語去詮釋, 但可以肯定的是, 審美情感和對美的認知大部分是從空間衍生出來 的。雖然直接從藝術理論的角度, 還不能真正表達建築空間所存在的價值, 但從使用的實用性來看, 空間的 合理使用理毫無疑問是學習建築學的目的。

建築大師路易斯 - 巴拉幹曾說: “我相信有情感的建築。“建築” 的生命就是它的美。這對人類是很重 要的。對一個問題如果有許多解決辦法, 其中的那種給使用者傳達美和情感的就是建築。” ${ }^{3}$ 由此可見, 這給 我們展示了建築的存在不僅僅是在我們存在的三維空間中, 是立體的, 它同時是物, 也是有感情的, 這個感 情賦予了建築超脫於物存在的另一個維度, 即心靈的維度空間,而建築藝術本身就是這個維度空間的中心。 在各種藝術中, 唯有建築能賦予空間以充分完全的價值存在, 建築空間的內部用來容納很多人和物, 要想從 中獲得美感的體驗和安全感, 只有建築才能提供。建築師布魯諾 - 賽維認為, “建築在藝術領域中處於一種 相對卑微的地位, 其原因在於大多數場合下, 建築物事實上被當作雕刻品或繪畫作品那樣來評價, 也就是當 作單純的造型現象, 就其外表進行表面的品評, 使建築學永遠只能從屬於雕刻與繪畫的範疇, 丢掉了建築獨 特的重要的本質特徵。而這種本質特徵就是空間, 唯一使建築有別於所有其他藝術的特徵就在於空間。為 了使建築學獲得獨立的地位與體系, 唯有將建築作為藝術化了的空間來進行理解。” (4) 由此可見, 建築本身的 唯一特性就是空間性,這是與其他藝術門類不太一樣的特徵,可以說建築是藝術化的空間。

弗西倫說道“建築藝術本身深藏的獨特性在於其內部體量, 建築藝術通過賦予這個特定的空間以確定 
的外觀, 而創造了其獨自的天地。更大的妙處還在於一種反轉的空間概念的創造, 人總是在每樣物件的外 部進行活動的,他總是處在其外,若要進行任何表面之内,他就必須把它打破才能進去。建築藝術則在所有 各種藝術中獨具一種特權, 不論是建造住宅、教堂或室內空間, 都有不是為了蓋一個使用方便的空處而已, 倒是要構成一個內部世界,其空間與光線是按幾何、按力學、按光學等規律來衡量,這些規律包含於自然界 事物的秩序之中 ....... ${ }^{5}$ 理論上來說,如果把空間當做是建築的核心, 建築本身通過空間形成外部和內部的 交合, 來表達它存在的意義, 以及用自己媒介的身份幫助人們去感知世界,那麼建築所形成的空間,它的存 在, 是符合人類生存得以延續所必備的條件。但是如果只當它是靜止的物質化存在的產物來看, 那是荒沙 難稽的。無論是現實空間, 還是虛擬空間, 建築都是物質和精神二者相結合的必然產物, 這一點從人類的文 化藝術史上就不難看出,建築存在的文明和人類文明的進化同樣年久。

\section{三、電影中“景”的表現}

斯坦利・庫布裏克說: “銀幕是一個如此神奇的媒介, 它能傳達情緒與感情的同時仍然饒有趣味。我想 這是任何其他形式的藝術無法企及的。” ${ }^{\circ}$ 銀幕的每一幀畫面就像一個風景一樣, 我們在看景的同時,也會身 在其景中。因此電影中的“景” 的藝術形式是多元化的一個綜合體。在電影這門動態的藝術裏,時間和空間 是同時存在的,電影要想延續,需要時間上在畫面故事裏的塑造,空間則是電影運動的一個延續。電影的藝 術思維是決定於電影空間的一個決定性因素, 電影的動態意識隨著社會的各種綜合因素的變化, 也推動了 電影空間思維的變化和發展。

由於電影藝術相比於其他藝術形式, 年代較新, 電影發明後, 有很長的一段時間, 人們只是把它看作是 一種記錄現實的手段,因此算是一門比較年輕的交叉學科的藝術門類。電影中的 “景”,其實特指的是電影 當中的虛擬空間,基本是影像三維與銀幕二維平面的虛實結合體。電影畫面的空間感, 是由於畫面的平面 構圖和人的視覺所產生的幻覺交叉複合所造成的。電影製作者必須圍繞銀幕二維和三維交叉結合的特性, 通過電影的空間思維, 實現電影畫面動態影像的營造。包括電影中的風景位置, 人物所處的位置, 人物的對 白和人物的表情等等形態來進行空間影像的接近真實的表達。而電影的這些所謂的 “景”,我們把它成為電 影中的空間形態,其實有點類似攝影, 但又有不同。而電影空間與其他藝術形式, 比如建築、攝影、繪畫, 塗 鴉等造型藝術的質的不同就在於電影具有運動性,可以說電影是一個流動的藝術。

同時,電影中的 “景”,也可以說是指電影的心理空間,這個是內化的, 就是電影中人物情感化了的無形 空間。這種心理空間,不再是在現實生活中所感受的那種直觀可以言喻的, 它是根據電影中的劇情安排所 展開的那種心理暗示的複雜情緒的表達, 是電影中人物塑造的內心變化和現實中觀眾對人性空間所認知的 某種推測。心理空間的畫面, 雖然可能感受到的只有鏡頭, 人物的語言和人物的行為, 以及電影中所營造的 空間氛圍, 但是也只有這樣的場景, 才能讓觀者感同身受, 理解電影場景中人物心境。這種心理空間從某種 程度上也會逐漸上升到哲學的角度,通過心理空間而傳達人物要表達出的某種意識,宣揚某些理念, 引導人 們思考。無論電影中是以景引理,還是借景傳理, 都是主觀世界的理性認識, 像有關隱喻、象徵、比擬、雙關、 對比、暗示和一切理性蒙太奇鏡頭的畫面空間,都具有觀念空間的性質。

\section{四、電影和建築的融通共生}

令人震撼的心理活動體驗、身臨其境的視覺特效以及我們回味無窮的故事情節, 是電影的空間藝術帶 給人們的直觀感受。建築靈活合理的空間佈局和光影的視覺衝擊, 結合宏偉或具有美學意義的造型效果, 是建築帶給人們的藝術享受。電影和建築都各自具有獨特的時空數據結構。建築中的空間被認為是死氣 沉沉的靜態元素的存在, 只是三維空間中的一種物理測量。而電影往往是時間軸心來描述事物的發展方 
向, 在影片中加人空間變化的元素, 可以讓人更直觀地感受電影的魅力。電影被建築師作為一種表達建築 平面圖的工具, 讓人們從多個角度更清晰、更方便地感知建築的美感。而建築在電影中也被用來營造一種 特殊的場景氛圍,給人們更多的情感心理暗示。

電影中的時間與空間進行複合, 構成電影整體的支架。電影空間, 給螢幕以具體的真實表現和空間形 式感受電影的時間。然後,給螢幕形象和空間形式以運動屬性和生命力。如果抛棄電影中的時間元素,螢 幕裏的內容世界就會隨著支架的斷裂而崩塌。在電影進行創作中, 只要我們藝術形式表現研究重心在空間 的內部, 都將直接導致支點的偏移,功能的改變和風格的變異。這也與當代電影在時空範疇上的審美走向 有關。電影是記錄和揭示現代科技手段的物質運動的手段,電影藝術是運動的藝術, 是物質和精神運動存 在的必然產物, 那麼, 如果你放棄空間, 也失去了空間運動的連續過程, 即失去了電影本身存在的意義, 電影 將失去生命的光彩。

據形式美法則創造出來的建築空間自身的美感。現代建築引人了時間的元素,構成了建築的“四維空 間”。“四維空間”建築概念的誕生,創造了建築的時空藝術。所謂“時空”即時間和空間,我國著名建築學家 沈福煦曾提出過“一個比較完整的建築需要進行形式、功能、時間和空間四個基本要素之間共同發展組成” 的理論。我國著名建築學家沈福煦曾提出過 “一個完整的建築需要形式、功能、時間和空間四個要素共同組 成” 的理論。 ${ }^{8}$ 一個建築的生命和人的生命一樣, 它存在於世界上的時間畢竟是有限的,但是又跟人類的有限 生命不太一樣, 建築並不會死亡、不會隨建築本體的埋塌而消散的是建築的精神。另一方面從藝術角度來 看, 不同的建築在不同時刻帶給人們的體驗感受也不一樣。建築以一天或一年為時間單位,通過光影、植物 和環境的變化, 給人以不同的視覺和其他藝術效果。例如日本著名建築師安藤忠雄的成名代表作一一光之 教堂(如圖 3), 因在教堂其中一面朝陽的牆面上開了一個十字型的洞, 而營造了特殊的光影效果, 尤其是在 原先黑暗的空間裏, 突然從外部射進來十字的光, 給人一種震撼和純淨。建築的造型簡潔大方,利用了一天 的光影效果提高了建築的表現力, 很多電影中也借鑒了安藤忠雄的設計方法,通過建築光影營造空間帶來 的神聖感。

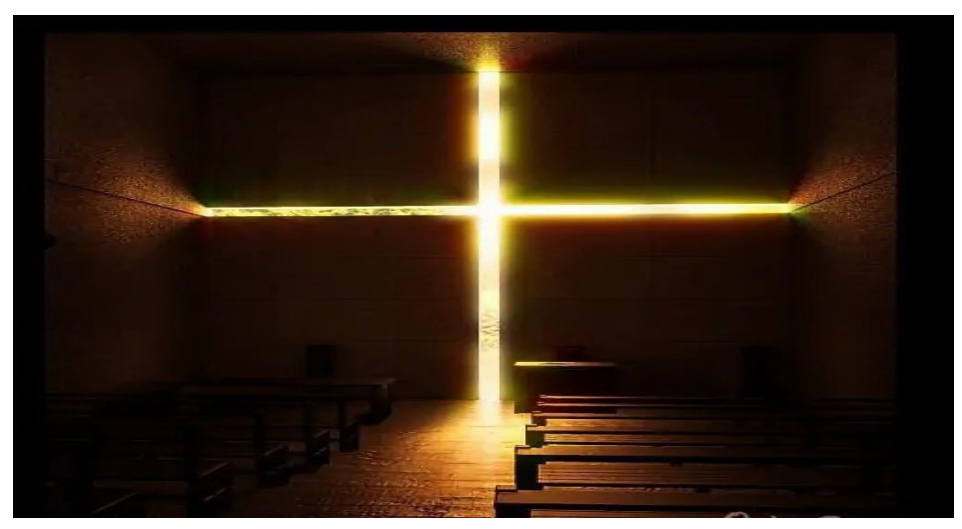

圖 3 安藤忠雄《光之教堂》

(來源: 網路 https://www.sohu.com/a/329269537_120084557)

\section{結語}

電影界與建築界的交流活動日益頻繁, 電影與建築的碰撞也產生了越來越多的火花。一部電影不能由 一個導演來塑造,一座建築不能由一個建築師來建造, 好的導演和建築師不能局限於他們自己的藝術圈, 藝 術需要與藝術交流。在這個世界電影和建築企業已經上升到一定的高度, 也可以說中國已經發展進人一個 瓶頸期的時代,這兩種藝術的對話我們可以通過讓我們跳出那些問題已經老舊的被視為常規的束縛, 從一 個崣新的角度進行重新瞭解電影與建築。 
因此, 建築的設計就像電影的製作一樣, 所以電影和建築可以融合並共存是有道理的。建築的造型和 空間感可以給予電影穿越的鬼力, 而反過來建築也可以對電影進行截取和意識營造鋪熱, 通過影像技術的 整理和重構走進大眾視野。世界有很多建築, 我們本身並沒有時間去領略它的建築風采, 更多的是通過電 影的媒介而瞭解和認知。因此, 當這兩種綜合藝術的大師們如此深人地融合在一起時, 他們就成為公共藝 術不可或缺的一部分,成為一種更具生命力的新綜合藝術。

\section{注釋}

(1) 雷拿:《時間、空間、情感電影中的建筑環境表達》,武漢理工大學 2005 年碩士論文, 頁 16 。

(2) [瑞士] 弗雷格阿爾瓦・阿爾托:《阿爾瓦・阿爾托全集》, 中國建筑工業出版社 2007 年版, 頁 64-70。

(3) 《大師系列》叢書编輯部:《路易斯・巴拉幹的作品與思想》, 中國建筑工業出版社 2006 年版, 頁 126-127。

(4) [義大利]布鲁諾・賽維: 《現代建筑語言》, 中國建筑工業出版社 2005 年版, 頁 69-71。

(5) 童明: 《空間神化》,《建筑師》2003 年第 5 期, 頁 $18-31$ 。

(6) [美] 米歇爾・希翁:《斯坦利・庫布裹克》, 北京大學出版社 2019 年版, 頁 132-135。

(7) 沈福煦:《中國建築史》, 上海人民美衍出版社 2015 年版, 頁 20。 